Institute of $\mathbf{F}_{\text {ood and }} \mathbf{A}_{\text {gricultural }} \mathbf{S}_{\text {ciences }}$

\title{
Blueberry Varieties for Florida 1
}

\section{J.G. Williamson and P.M. Lyrene ${ }^{2}$ \\ Introduction}

Blueberries are native to eastern North America. They are one of the few crop plants that originated here. The rabbiteye blueberry (Vaccinium ashei) occurs mostly in certain river valleys in northern Florida and southeastern Georgia. The highbush blueberry (Vaccinium corymbosum) is native in the eastern third of the United States and southeastern Canada. Florida is rich in other native Vaccinium species. The woods and swamps of Florida are populated with at least eight wild blueberry species. No area of the state lacks wild blueberries, except where soil $\mathrm{pH}$ is above 6.0.

A short-lived commercial blueberry industry was established in Florida over a century ago when wild rabbiteye blueberries were transplanted from the woods to cultivated fields. This may have been the first attempt to cultivate blueberries commercially anywhere in the world. However, the enterprise was short-lived because of poor fruit quality and marketing problems. During the next few decades there was little interest in commercial blueberry production in Florida. However, during the 1960s small plantings of rabbiteye blueberries were established for local consumption. During the 1960s and 1970s, rabbiteye blueberries were not planted in
Florida for commercial harvest, packing and shipping because they flower late, have long fruit development periods and actually ripen later than highbush blueberries grown in North Carolina. After 1950, highbush acreage in North Carolina and the northern states expanded rapidly. These highbush varieties could not be grown in Florida because they had a high chilling requirement.

In 1976, the University of Florida blueberry breeding program released three new southern highbush blueberry varieties which were bred specifically for Florida's mild climate and showed promise for producing early-ripening, good quality fruit. By 1983, a small blueberry shipping industry was established in Florida. Because Florida's southern highbush blueberries ripen earlier than blueberries from other areas, they brought very high prices. High prices and ready markets have lead to expansion of Florida's blueberry acreage. Between 1982 and 2002 Florida blueberry acreage has increased from less than 1000 acres to approximately 2000 acres and additional plantings are anticipated. During the 1980s and early 1990s more than half of the Florida blueberry acreage consisted of rabbiteye varieties. During the last decade, most new plantings have been southern highbush varieties. Southern highbush varieties, on average, ripen 4 to 6 weeks

1. This document is HS967, one of a series of the Department of Horticultural Sciences, Florida Cooperative Extension Service, Institute of Food and Agricultural Sciences, University of Florida. Original publication date: March 2004. Please visit the EDIS Web site at http://edis.ifas.ufl.edu.

2. J.G. Williamson, professor, and P.M. Lyrene, professor, Horticultural Sciences Department, Cooperative Extension Service, Institute of Food and Agricultural Sciences, University of Florida, Gainesville, FL 32611.

The Institute of Food and Agricultural Sciences (IFAS) is an Equal Employment Opportunity - Affirmative Action Employer authorized to provide research, educational information and other services only to individuals and institutions that function without regard to race, creed, color, religion, age, disability, sex, sexual orientation, marital status, national origin, political opinions or affiliations. For information on obtaining other extension publications, contact your county Cooperative Extension Service office. Florida Cooperative Extension Service / Institute of Food and Agricultural Sciences / University of Florida / Larry R. Arrington, Interim Dean 
earlier than rabbiteye varieties. Currently, well over half of the total Florida acreage is southern highbush and virtually all plantings established during the last 8 years for commercial shipping are southern highbush. A survey in 1999 indicated that about one-third of the total blueberry acreage in Florida was less than 3 years old. Many new southern highbush plantings have been established in the central Florida counties of Polk, Hillsborough, and Lake, while several large rabbiteye plantings in north and northwest Florida have been abandoned.

As many new southern highbush plantings have come into bearing, annual statewide blueberry production has steadily increased from about 1.5 million pounds in the early 1990s to over 3.5 million pounds in 2003. Fresh fruit prices have remained high for early-ripening southern highbush varieties. However, production problems have been many and severe. Although many aspects of blueberry growing in Florida are better understood than they were a decade ago, blueberries remain a difficult crop to grow in Florida.

The major incentive for growing blueberries in Florida is the excellent market window available for blueberries that ripen before May 20. In recent years, blueberries have been planted in the southern hemisphere for shipping to the northern hemisphere during the period from November to March. Southern highbush varieties are being planted along the Gulf Coast from south Georgia to east Texas and in California. Nevertheless, the market period from April 1 to May 10 is still available almost exclusively to Florida growers, and fruit prices are usually high until late May when harvest of the North Carolina crop begins.

\section{Blueberry Varieties}

Two types of blueberries are grown in Florida; southern highbush and rabbiteye. The earliest ripening southern highbush varieties ripen about 4 to 6 weeks earlier than the earliest rabbiteye varieties grown at the same location. Because they ripen earlier, southern highbush normally bring much higher prices than rabbiteye berries.

Rabbiteye blueberries grow best in regions of Florida where winters are as cold or colder than those in Ocala. Depending on the variety, southern highbush blueberries may be adapted from Sebring, Fla., up the Florida peninsula, into southeastern Georgia. Overhead irrigation for freeze protection is generally required for reliable fruiting of southern highbush blueberries because they flower so early. Cross pollination between, or among, varieties is needed for maximum production for both types of blueberries. Therefore, multiple varieties are needed of either southern highbush or rabbiteye. Rabbiteyes are needed to pollinate other rabbiteyes and southern highbush are needed to pollinate other southern highbush.

\section{Southern Highbush Varieties. Southern} highbush blueberries were developed by crossing northern highbush varieties from Michigan and New Jersey with wild blueberries native in Florida and other southeastern states. The first three southern highbush varieties were released from the University of Florida in the mid 1970s. Since then, many newer and improved southern highbush varieties have been released.

Southern highbush blueberries grown in peninsular Florida are the earliest blueberries to ripen in North America. These are the varieties that are currently grown for commercial shipping in Florida. Southern highbush blueberries are generally considered more difficult to grow than rabbiteyes. Very early flowering makes southern highbush blueberries quite susceptible to late winter/early spring freezes. Southern highbush blueberry plantings without overhead irrigation for frost protection frequently lose their crops as far south as Highlands County. Moreover, compared to rabbiteye varieties, southern highbush blueberries are less forgiving in soil requirements, more susceptible to excessive soil moisture and drought, and generally more susceptible to a number of diseases such as Phytophthora root rot and blueberry stem blight than are most rabbiteye varieties. Because of their early ripening season, southern highbush blueberries are particularly attractive to birds (especially cedar waxwings). Bird damage has been quite severe on some farms in some years. Prospective southern highbush growers should be aware of establishment costs such as freeze protection, which requires overhead irrigation, and 
soil preparation, which usually requires large quantities of pine bark.

Rabbiteye varieties. On suitable blueberry soils in north and north central Florida, rabbiteye blueberries are more vigorous, longer lived, and easier to care for than most southern highbush varieties. They are more drought tolerant than southern highbush blueberries and can grow satisfactorily in soils which are lower in organic matter. Currently, commercial rabbiteye blueberry production is not recommended for areas with winter temperatures milder than in Ocala because of the possibility of inadequate chilling. On the other hand, severe crop losses to spring freezes are not uncommon in north Florida, especially for early-season rabbiteyes which bloom before mid- to late-season rabbiteyes. For home gardeners and u-pick growers, late flowering varieties such as Powderblue and Brightwell usually produce good crops without freeze protection at most locations in northern Florida.

Rabbiteye fruit is generally firmer than southern highbush and, in many cases, they are capable of being mechanically harvested for the fresh market. However, berries of highbush and rabbiteye are enough alike that most consumers do not distinguish between the two. Generally, rabbiteyes are better suited for u-pick and local sales while southern highbush are better suited for commercial shipping. Rabbiteye blueberries grown in Florida can be divided into early-, mid-, and late-season varieties. Home gardeners and u-pick growers who do not require an early harvest season will find that mid- and late-eason varieties are more reliable in fruiting.

\section{Early-season Rabbiteye Varieties}

During the early to mid 1980 s, more than 500 acres of Aliceblue, Beckyblue, Climax, and Bonita were planted in north-central Florida for the fresh fruit shipping market. At that time, these were the earliest-ripening rabbiteye varieties grown in North America. They ripened about two weeks before Climax and Premier grown in Alma, Georgia, and slightly before, or about the same time as, Croatan the principal highbush variety being grown in North Carolina. Yields of early-season rabbiteyes grown in Florida have often been disappointingly low. Various factors including spring freezes, insufficient bee populations to obtain complete pollination, blueberry gall midge and thrips damage to flowers, and leaf diseases that result in early fall defoliation may be involved.

Recent observations by growers and researchers suggests that the low yields of these rabbiteye varieties may have been largely the result of thrips and gall midge damage to developing flowers and fruit. Efforts to control these pests more thoroughly in rabbiteye plantings have resulted in favorable yield responses. However, even the early-ripening rabbiteye varieties do not ripen early enough in the season to be the best choice for fresh fruit shipping. They are better suited for extending the early end of the harvest season for local sales and u-pick operations. Commercial shipping operations in Florida should grow southern highbush varieties that are discussed later. Descriptions of the more common early-season rabbiteye varieties are as follows.

Austin - A new variety released by the University of Georgia that ripens a few days after Climax. Its yields have been good compared to other early-ripening rabbiteyes in northern Florida.

Beckyblue - A 1977 release from the University of Florida which can be mechanically harvested for the fresh market. Fruit have good color, size, and firmness and a dry picking scar. Problems with early defoliation due to leaf diseases can reduce flower bud initiation. Older plants have benefitted from rejuvenation pruning to maintain adequate flower bud initiation. A low chilling requirement of $300-400$ chill hours often results in very early flowering and susceptibility to spring freezes.

Bonita - A 1985 release from the University of Florida which can be mechanically harvested for the fresh market. Fruit ripen about three days after Climax and have good size, color, and firmness with a dry picking scar. Plants are moderately vigorous and develop a dense bush with many canes. It generally has the same problems as Beckyblue with leaf diseases, early defoliation, and poor flower bud initiation. It requries 350 - 400 chill hours. 
Climax - a 1976 release from the University of Georgia which has concentrated ripening and can be machine harvested for the fresh market. Fruit are medium in size and have a small scar and good flavor. Climax flowers more heavily and reliably than Beckyblue or Bonita. It is highly susceptible to the blueberry gall midge. It requires 450 - 500 chill hours.

Premier - a release from North Carolina State University which is vigorous and productive with excellent fruit color, size, and flavor. Canes on young plants may not support heavy crop loads. It is highly susceptible to blueberry gall midge and should not be planted without a spray program to control this insect. Its chilling requirement is estimated at 550 chill hours.

\section{Mid- and Late-season Rabbiteye Varieties}

The mid- and late-season rabbiteye varieties have generally been more productive in north peninsular Florida than the early-season rabbiteyes. Mid- and late-season varieties ripen in northern Florida after the North Carolina crop is on the market. In Florida, these varieties are commonly grown on u-pick farms. Trials at the University of Florida Research and Education Center in Monticello showed that mid- to late-season rabbiteye varieties are well adapted to northwest Florida while early-season rabbiteyes and southern highbush varieties are routinely frozen-out without freeze protection from overhead irrigation. The more commonly grown mid- to late-season rabbiteye blueberry varieties for Florida are discussed below.

Brightwell is a 1983 University of Georgia release which is vigorous, upright, and an excellent producer. Fruit are medium in size with a small dry scar and good flavor and may be mechanically harvested for the fresh market. It probably is the best rabbiteye variety currently available. The fruit ripen after Climax; about the same time as Woodard. It has been highly productive as far south as Gainesville. Its chilling requirement is estimated at 350-400 chill hours.

Chaucer is a high yielding variety released by the University of Florida which is vigorous and spreading. Fruit are medium in size and have a wet picking scar. A possible choice for u-pick purposes but not recommended for machine harvest or for commercial shipping. Its chilling requirement is estimated at 350 - 400 chill hours.

Powderblue is similar to Tifblue in season, appearance and harvesting characteristics so that the two can be harvested together. Powderblue usually cracks less and hangs on the bush better than Tifblue. Powderblue is considered a very reliable producer in northern Florida. Its chilling requirement is estimated at 350-400 chill hours.

Tifblue is an older variety released from the University of Georgia that has been widely planted in southeastern Georgia and to a lesser extent in northern Florida. Plants are vigorous, upright, and productive. It has serious problems with fruit cracking during wet weather. Powderblue appears to be replacing Tifblue this season.

\section{Southern Highbush Varieties}

Beginning in the late 1980s, southern highbush began to replace rabbiteye as the blueberry of choice for fresh fruit shipping within and from Florida. Currently all Florida blueberry plantings that are grown for fresh fruit shipping are southern highbush varieties. Some of the more common southern highbush varieties are described below.

Bluecrisp is a patented release from the University of Florida which appears to be well adapted to 400 - 600 chill hour zones of northern Florida and southeastern Georgia. Bluecrisp is a moderately vigorous plant that tends to have a spreading habit and leafs strongly after flowering in the Gainesville area. Berry size is similar to Sharpblue and the scar is dry but medium deep. The unique characteristic of Bluecrisp is the unusually high fruit firmness that gives it its name. This unusually high fruit firmness may enhance consumer appeal and increase shelf life of the fresh berry. Bluecrisp has not been popular with Florida growers because its yields are only medium and it typically ripens from April 24 through May 16, about a week later than Star. Bluecrisp has produced higher yields in southeastern Geogia than in northern Florida. In southeast Georgia, it has a high incidence of cane 
die-back of unknown cause. Bluecrisp is more susceptible to leaf rust than most varieties.

Emerald (Fig. 1) was released as a patented variety by the University of Florida in 1999, and is currently one of the more widely planted varieties in north-central Florida. Emerald combines a vigorous, upright, bush with high yield potential, early ripening, and large, high-quality berries. Emerald flowers open uniformly, and it produces abundant leaves even after mild winters in Gainesville.

Because the plant is highly vigorous when planted on suitable soils, Emerald is capable of carrying heavy crops. Emerald normally reaches full bloom in Gainesville about February 15, and overhead irrigation is needed to protect flowers and fruit from freezes in February and March. First harvest occurs a few days earlier for Emerald than for Sharpblue and Star in Gainesville. About $90 \%$ of the fruit of Emerald is normally ripe between April 19 and May 15 in Gainesville.

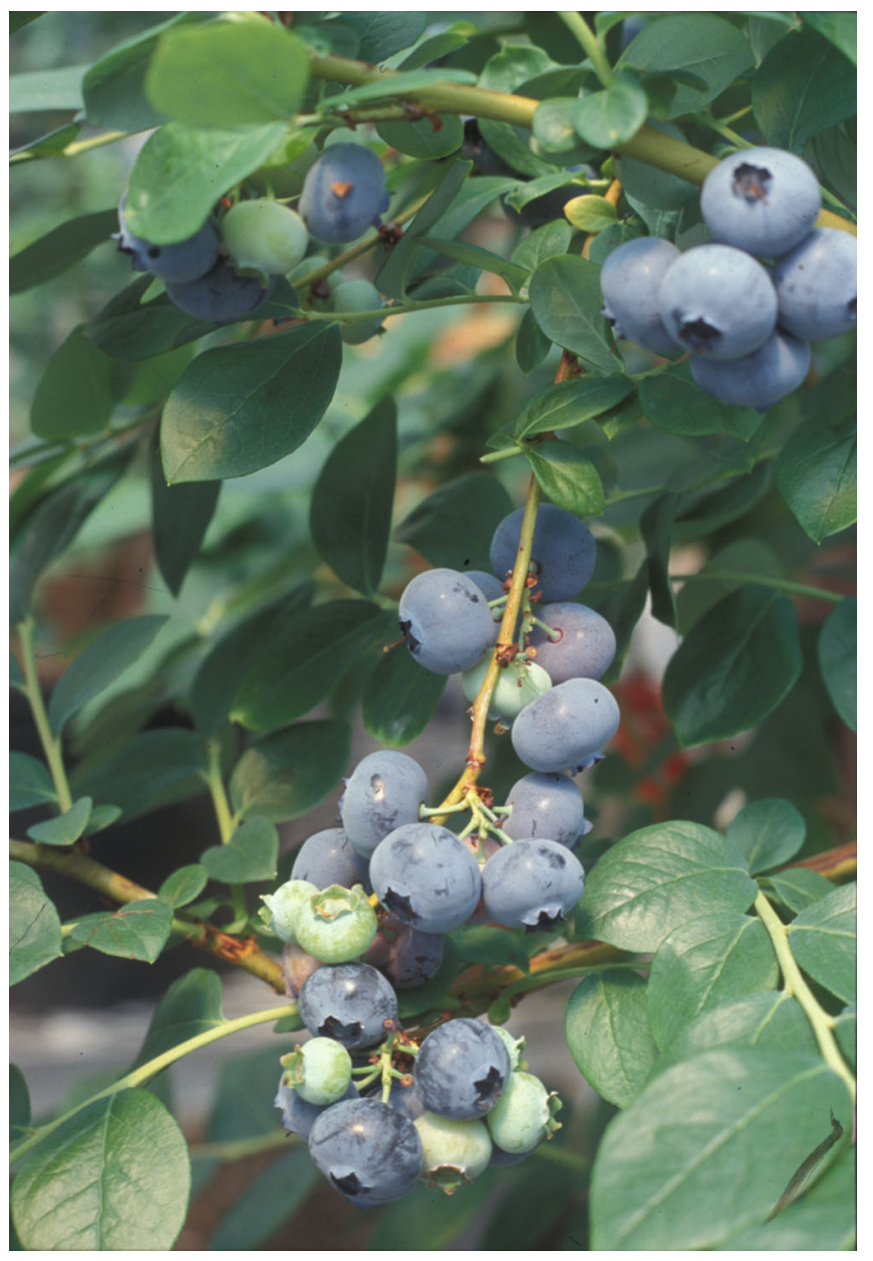

Figure 1. 'Emerald' blueberry.
Gulf Coast was released by the USDA in 1987. It is not patented and may be propagated without restrictions. Plants are vigorous, semi-upright with medium to high productivity. Fruit are medium in size and firm with good flavor. Gulf Coast has been widely used as a pollinizer for Sharpblue and Misty. It has preformed better than most varieties in southwest Florida. A major problem associated with Gulf Coast is a tendency for stems to remain attached to fruit during harvest. This can cause additional expense during picking and grading. Gulf Coast remains one of the more widely grown varieties south of I-4.

Jewel (Fig. 2) is a patented release from the University of Florida breeding program with a moderately low chilling requirement, very early ripening, and high berry quality. In Gainesville, Jewel typically flowers about February 16 and begins ripening about 5 days earlier than Sharpblue. The average date when commercial harvest for Jewel begins in Gainesville is about April 15 and harvest is normally finished by May 12. Jewel produces a large number of flower buds but leafs well in the spring. Vigor is about equal to Sharpblue but Jewel is shorter and more spreading than Sharpblue. Berry quality is excellent but tends to be tart until fully ripe. Berry size is about equal to Sharpblue, but firmness and scar are much better than Sharpblue. Jewel may be considered for trial from Ocala north into SE Georgia. In central Florida, Jewel has looked good in some fields, producing large early berries but these plantings are still young. Jewel is moderately susceptible to Phytophthora root rot. Overhead irrigation is recommended for freeze protection wherever Jewel is grown.

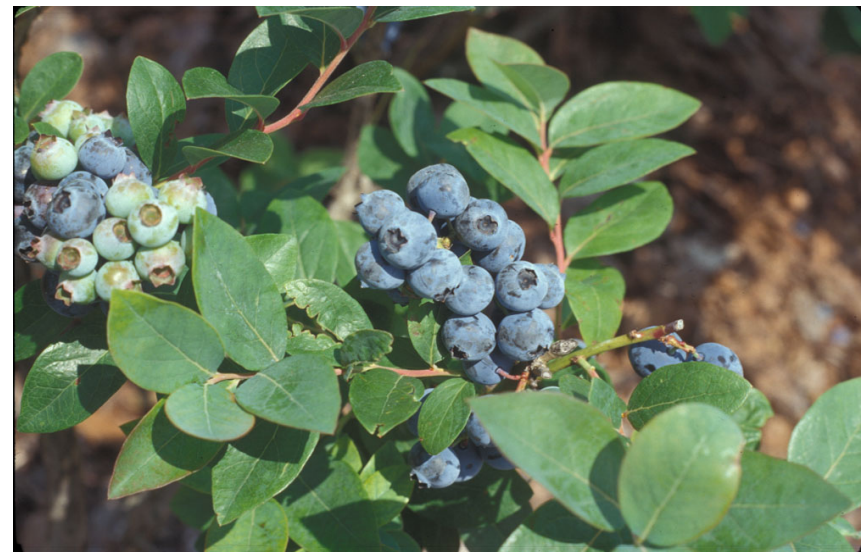

Figure 2. 'Jewel' blueberry. 
Millennia (Fig. 3) was released as a patented variety by the University of Florida breeding program in 2001. It is one of the more widely planted varieties in north-central Florida. Millennia is medium to high in vigor and has a spreading, rather than an upright, growth habit. It produces a heavy load of flower buds in the fall, and young plants should be winter pruned the first 2 years to prevent over-fruiting and to enhance early leafing. Older plants may require either Dormex application or winter pruning to increase leafing and/or reduce the flower load. The average date on which Millennia reaches $50 \%$ open flower is about Feb. 16 in Alachua County. In Alachua County, first commercial harvest on Millennia (10\% of fruit ripe) averages about April 15, and the first half of the berries are normally ripe by April 28. The berry of Millennia is large to very large on well-leafed bushes that are not overloaded. Millennia berries are very firm, equal to Star. The picking scar is good to excellent. The flavor is good, although it can be somewhat bland on poorly-leafed or overloaded plants.

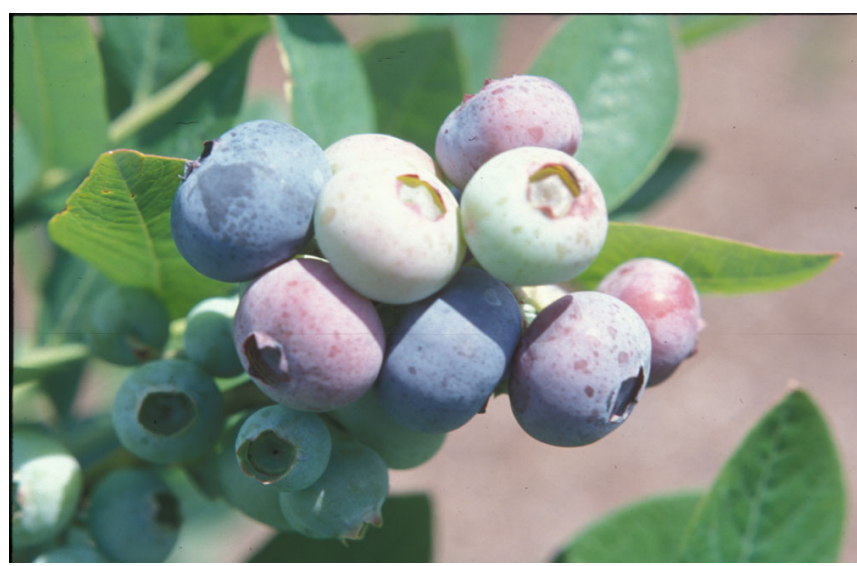

Figure 3. 'Millennia' blueberry.

Misty (Fig. 4) was released by the University of Florida in 1992. It is not patented and may be propagated without restrictions. Its bloom and harvest season are similar to Sharpblue and for many years it was the major pollinizer for Sharpblue in Florida. Fruit quality is excellent on plants that do not overbear. However, plants tend to have very heavy flower bud set and produce an overabundance of fruit and leaf poorly in the spring. The stress associated with the heavy crop load and poor leafing often leads to severe infections of blueberry stem blight. It is extremely important with this variety to remove all fruit and flowers from one and 2-year old plants.
Heavy winter pruning and use of Dormex have partially alleviated the problems associated with overbearing and poor foliation. Misty is gradually being replaced by superior varieties.

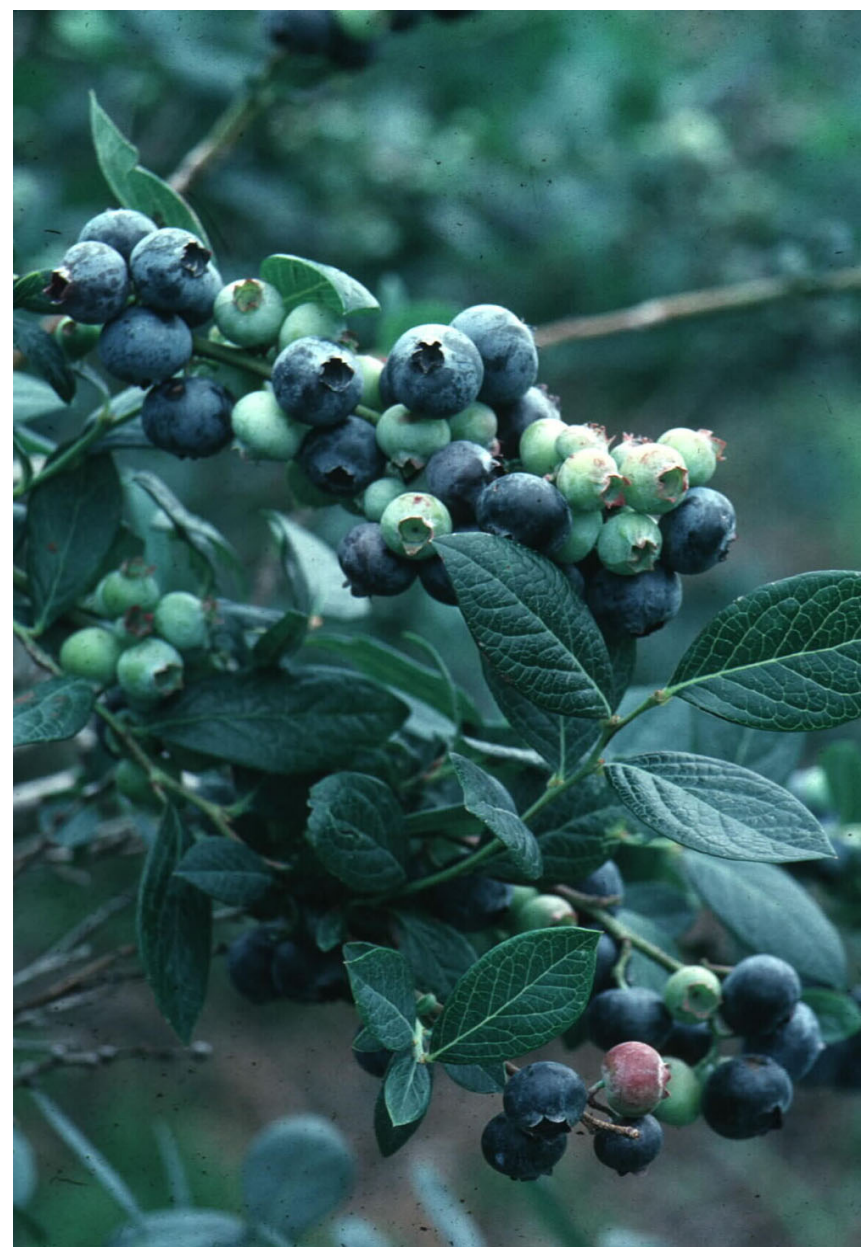

Figure 4. 'Misty' blueberry.

Santa Fe is a patented release from the University of Florida blueberry breeding program. It appears to have a chilling requirement of about 400 hours making it higher in chilling than Sharpblue or Gulf Coast (about equal to Star). It has received sufficient chilling in each of the past 10 years in Gainesville and has fruited well in the southeast corner of Alachua county. Santa Fe is probably not well adapted to areas south of Alachua County. In Gainesville, even with Dormex, flowers may be slow to open in the spring. Where flower bud set is excessive, winter pruning is required to promote adequate dud break. Santa $\mathrm{Fe}$ is strong, vigorous and upright, with early-ripening, high-quality, fruit. On average, Santa Fe reaches 50\% open flower about February 25 in Alachua County and harvest on Santa 
Fe begins about the same time as on Sharpblue. Berries are light blue with excellent flavor, scars and firmness. Santa Fe is difficult to propagate by cuttings. Santa Fe may be of interest to growers in southeast Georgia because of its high vigor, disease resistance, and because it flowers later than most other Florida varieties.

Sapphire (Fig. 5) is a low-chill southern highbush blueberry that is recommended mainly as an early-season variety in areas south of I-4 where blueberries can be commercially grown. In Alachua County, Sapphire reaches 50\% open flower about February 18. First commercial harvest of Sapphire in Alachua County averages about April 16 and harvest is complete before May 15. Ripening is more concentrated on Sapphire than on Sharpblue. Fruit color and size are comparable to Sharpblue and Misty. The picking scar is dry and fruit are firm. Sapphire is not as vigorous as Sharpblue and tends to set large numbers of flower buds which may require thinning for adequate vegetative growth. The plants may be slow to establish during the first 2 to 3 years after planting. Because of its low vigor, Sapphire should only be planted on good blueberry land or in pine bark beds. Overhead irrigation is recommended for freeze protection wherever Sapphire is grown. From Ocala north, Sapphire has been replaced by varieties with greater vigor, such as Star, Millennia, Jewel, and Emerald.

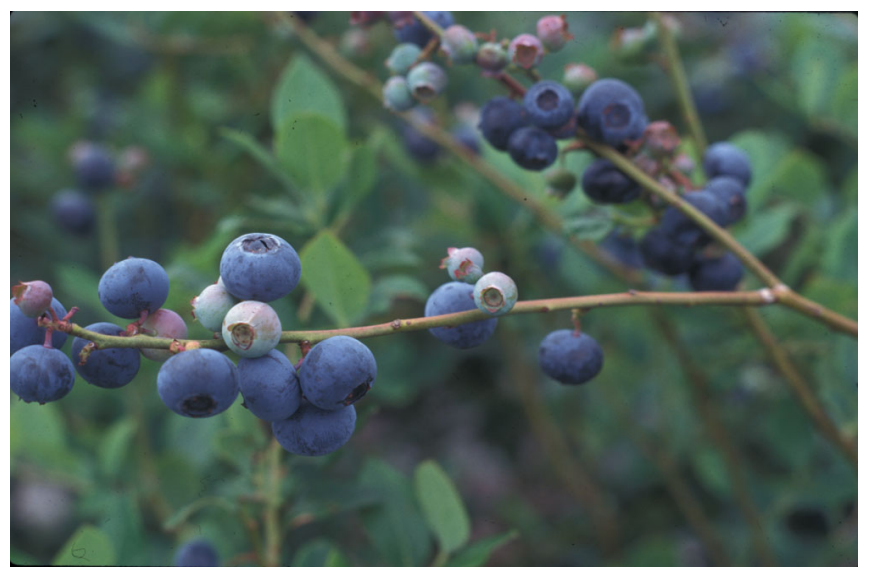

Figure 5. 'Sapphire' blueberry.

Sharpblue was one of the first southern highbush varieties released by the University of Florida (1976). It is not patented and may be propagated without restrictions. Fruit are medium sized with excellent flavor but the skin may tear during harvest. The mean date of open flowers is February 17 in Gainesville. The mean date of 50\% ripe fruit is May 1 in Gainesville. The plants are moderately susceptible to Phytophthora root rot and various leaf spot diseases, but they generally survive well in field settings. For many years Sharpblue was the major variety grown in Florida. However, it is no longer widely planted in Florida because of newer varieties with improved fruit quality characteristics and earliness.

Southmoon was released by the University of Florida in 1995. It appears well adapted to north Florida and SE Georgia. It flowers with Star but has a longer bloom-to-ripe period than Star. The harvest season is about 10 days later than Sharpblue and is normally complete by May 20 . When grown well, Southmoon has excellent berry quality. However, because it is quite susceptible to Phytophthora root rot and ripens 10 days later than Star, it has not been widely planted in Florida and is considered obsolete by most growers.

Star (Fig. 6) was released by the University of Florida as a patented variety in 1995. Star is slightly less vigorous than Sharpblue but its survival in the field is about equal to Sharpblue. Star holds its winter dormancy much better than Sharpblue and is less likely to bloom in January or early February. Average date on which Star reaches 50\% bloom in Alachua County is February 23. The first half of the berries are normally ripe by April 26. Star leafs well in Gainesville and southeastern Georgia. Star has a very short bloom to ripe interval and has a relatively compressed harvest period of about 3 weeks as compared to about 6 weeks for Sharpblue. Berries are excellent in size, firmness, and scar. Star appears to be best adapted to north Florida and southeastern Georgia. Star has not performed well south of Ocala where it tends to produce few flowers and has weak growth.

Windsor (Fig. 7) is vigorous, with stout stems and a semi-spreading growth habit. The mean date of $50 \%$ open flower in Alachua County averages about February 23. Windsor leafs out strongly as it begins to flower, and this strong leafing enables it to support a large crop. In Alachua County, the first commercial hand harvest on Windsor (10\% of the crop ripe) 


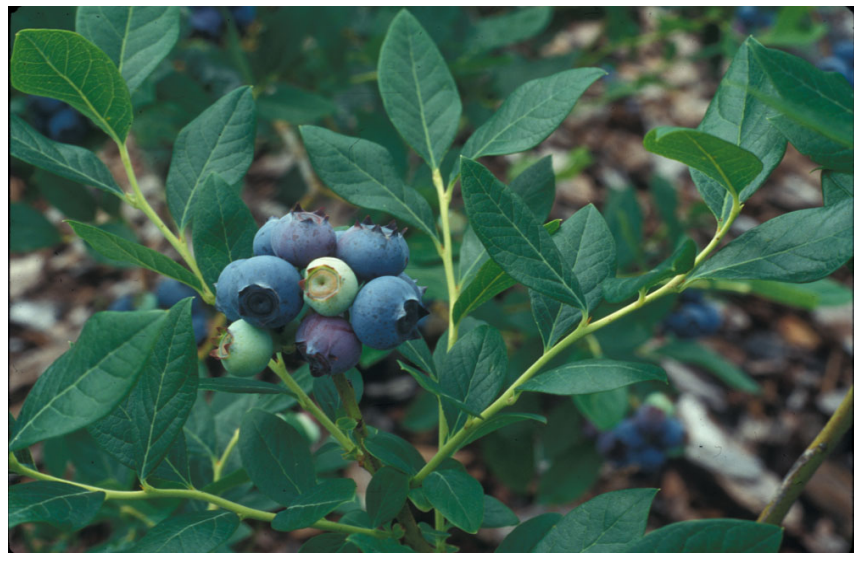

Figure 6. 'Star' blueberry.

averages about April 15, and 50\% of the berries are normally ripe by April 28. Windsor berries are very large. Berries from the first half of the harvest average about 2.4 grams on young vigorous plants. The berries are about the same color as those of Sharpblue and Star. It has good firmness and flavor. Although Windsor grows and fruits well, it has lost favor among growers because of the deep picking scar which complicates packing and reduces post-harvest life.

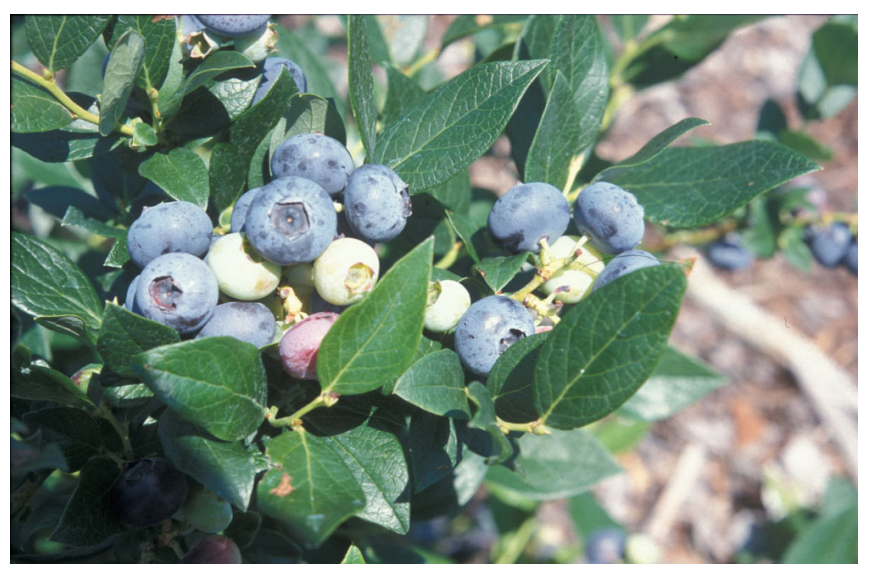

Figure 7. 'Windsor' blueberry.

\section{Patented Varieties: Legal Requirements}

The blueberry breeding programs in Florida, North Carolina, and Michigan are financed to a large extent by revenues from royalty payments on patented varieties. Most of the newer varieties developed by these programs are patented. Propagation of these varieties requires a license from the agency holding the patent. Planting a patented variety does not require a license if the plant was purchased from a licensed propagator. Propagation of patented varieties without a license is a violation of the law, even if you own the plants from which the cuttings are taken. To inquire about licenses for Florida varieties, contact Florida Foundation Seed Producers, Inc., P.O. Box 309, Greenwood FL 32443; phone (850) 594-4721; e-mail seed@digitalexp.com. Information about licenses for the University of Georgia varieties is available from Georgia Seed Development Commission, 2420 South Milledge Ave., Athens GA 30605; phone (706) 542-5640; E-mail www.gsdc.com.

\section{Conclusions}

Variety selection depends on where in Florida you are growing blueberries and on your marketing objectives. Both rabbiteye and southern highbush have their advantages and disadvantages, and specific varieties within each type have their own merits and deficiencies. Most commercial blueberry growers in Florida are interested in the early, fresh fruit market which usually is associated with excellent fruit prices.

Early-season rabbiteye varieties have not been consistently productive and they ripen later than the early southern highbush varieties. Therefore, most new plantings intended for the fresh market are early-ripening southern highbush varieties. Many southern highbush varieties are not well adapted to extreme north and northwest Florida because they flower early and hard freezes in February and March can greatly reduce yields. Even in central and south-central Florida, southern highbush growers must provide protection from late freezes, usually with overhead irrigation.

Rabbiteye varieties are commonly grown throughout north and northwest Florida for u-pick and for sale through other local marketing outlets. U-picked and locally marketed blueberries have recently become an underutilized marketing option, particularly for the small farmer, as most Florida growers aim for the high-priced commercial shipping market. 


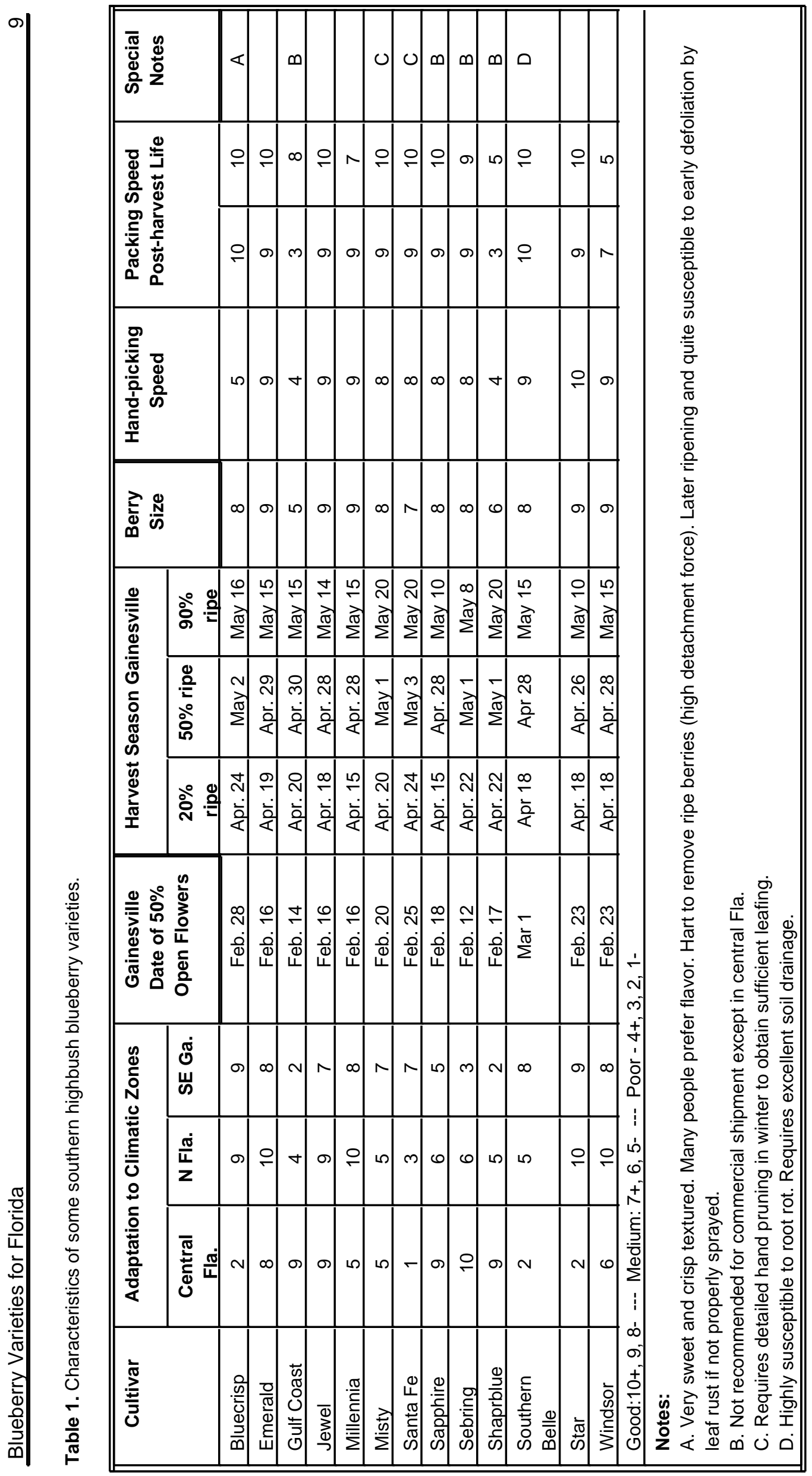

